\title{
The Metasemantics of Contextual Sensitivity
}

\author{
Jeffrey C. King \\ Rutgers University
}

Among the many contextually sensitive expressions in natural language, some have conventional context independent meanings that are such that when the expression is placed in a context, its conventional context independent meaning by itself suffices to secure a semantic value for the expression relative to that context. ' $I$ ' is the paradigm here. Some think 'today', 'here', 'now', and other expressions are of this sort as well. Following established usage, call such expressions pure indexicals. ${ }^{1} \mathrm{I}$ bring up pure indexicals only to make clear that I will not be concerned with them here.

Other sorts of contextually sensitive expressions are such that their context independent conventional meanings need to be in some way supplemented in context for the expressions to secure semantic values in those contexts. As we will see, it is not clear that there is a paradigm here, but 'he' used demonstratively is a clear example of such an expression. Call expressions of this sort supplementives in order to highlight the fact that their context independent meanings need to be supplemented in context for them to have semantic values relative to the context.

Many philosophers and linguists think that there is a lot of contextual sensitivity in natural language that goes well beyond the pure indexicals and supplementives like 'he'. Constructions/expressions that are good candidates for being contextually sensitive include: quantifiers (via "quantifier domains" being fixed in context); gradable adjectives ('tall', 'smart', etc.), including "predicates of personal taste" ('tasty', 'fun'); modals; conditionals; possessives ('Annie's book'); and relational expressions

\footnotetext{
1 There is a serious question as to whether any expression other than 'I' is a pure indexical. Even 'now', 'today', and so on can have their "extents" varied in context. Consider 'I am talking now.' versus 'People used to watch television shows exclusively on their televisions sets, but now they are just as likely to watch them on their computers.' It would appear that the "extent" designated by 'now' differs in these two sentences on their natural interpretations. It doesn't appear that this can be explained solely by reference to the context independent meaning of 'now'. So this at least casts doubt on the claim that 'now' is a pure indexical the way I am using the term.
} 
taking implicit arguments ('ready', 'enemy', 'finish'). It would appear that in none of these cases does the expression/construction in question have a context independent meaning that when placed in context suffices to secure a semantic value for the expression/construction in the context. In each case, some sort of supplementation is required to do this. Hence, all these expressions are supplementives in my sense.

For a given supplementive, the question arises as to what the mechanism is for supplementing its conventional meanings in context so as to secure a semantic value for it in context. That is, what form does the supplementation take? The question also arises as to whether different supplementives require different kinds of supplementation. Following Michael Glanzberg (2012), let us call an account of what, in addition to its conventional meaning, secures a semantic value for a supplementive in context a metasemantics for that supplementive. So we can put our two questions thus: what is the proper metasemantics for a given supplementive; and do all supplementives have the same metasemantics (of course the answer to the second question will fall out of answering the first question for all supplementives)?

In King (2012), I considered a special case of supplementives-demonstratives (i.e. second and third person pronouns, as well as single and plural simple ('that') and complex ('that girl') demonstratives) - and proposed a metasemantics for them. I suggested in that paper that my metasemantics plausibly applies to all supplementives. But I did not pursue the matter there and left it as a reasonable hypothesis, though I knew there were various difficulties that would have to be addressed.

Subsequently, I came across an illuminating paper by Michael Glanzberg (2012) in which he argues that there are two importantly different sorts of supplementives (which Glanzberg calls parameters). Overall, I find Glanzberg's argument convincing. However, one of his arguments that there are two different kinds of supplementives is that the two kinds are governed by different metasemantics. Obviously, if Glanzberg is right about this, the metasemantics I proposed for demonstratives in King (2012) cannot apply to all supplementives.

In the present work, I propose, first, to sketch the metasemantics I formulated for demonstratives in King (2012). Next, I will briefly consider a number of other supplementives that I think the metasemantics I propose plausibly applies to and explain why I think that. Finally, I will consider three arguments that Glanzberg gives to the effect that supplementives are governed by two different metasemantics, and attempt to respond to them. In each case, Glanzberg argues that certain supplementives are not governed by the sort of metasemantics I proposed for demonstratives, though Glanzberg does think my sort of metasemantics applies to some supplementives, including demonstratives. As I suggest above, even if my responses to Glanzberg are successful, I do not think this undermines the central conclusion of his paper; and there is a sense in which I may leave Glanzberg much of what is important to him even with respect to his claims about the metasemantics of supplementives. In any case, though I do not claim to show here that my metasemantics applies to all supplementives I think there is a good case that it applies to a large number. Further, I 
highlight one important sort of worry about whether my account applies to all cases, and suggest strategies for dealing with cases that initially appear to cause trouble for my account. Whether these strategies can handle all recalcitrant cases is unclear to me.

The best way to introduce and motivate my view is by considering the deficiencies of other views. Let us begin with the metasemantics for demonstratives given in Kaplan (1977). Kaplan held that demonstratives require an associated demonstration. The requirement was enforced by what Kaplan called "the linguistic rules"; and a demonstrative without an associated demonstration was held by Kaplan to be "incomplete." Presumably when Kaplan talks of the "linguistic rules" requiring that a demonstration accompanies each use of a demonstrative, he means that it is part of the lexical semantics of demonstratives that they require supplementation by a demonstration. A complete demonstrative in context refers to the thing that the demonstration demonstrates. Thus, for Kaplan (1977), it is the demonstration that determines a semantic value for a demonstrative in context. Call this metasemantics the demonstration account. ${ }^{2}$

Kaplan himself recognized that the demonstration account has various problems. Of course, the demonstration account requires that any time a demonstrative has a semantic value in context, that value was secured by a demonstration. The first problem is that in many cases it simply isn't clear what a demonstration is on this account. Kaplan writes:

However, a demonstration may also be opportune and require no special action on the speaker's part, as when someone shouts "Stop that man" while only one man is rushing toward the door. My notion of a demonstration is a theoretical concept. I do not, in the present work, undertake a detailed 'operational' analysis of this notion, although there are scattered remarks relevant to the issue. (1977: $490 \mathrm{fn} .9$ )

The speaker in this case clearly does secure a semantic value for his demonstrative in context. But what is supposed to be the demonstration that does so in such a case? It is quite unclear. There are other cases where it is, if anything, less clear what the demonstration is supposed to be. Your father, to whom you were very close, has just died. You used to attend New York Giant games together, and we both know that I know this. I am sitting with you when an ad for Giant tickets comes on television and I see a pained look on your face. I say: 'I know you miss him.' and succeed in referring to your father. Again here it is hard to know how to think of the alleged demonstration. So for the advocate of the demonstration account, there are many, many cases in which it just isn't clear what the demonstration is. But then the demonstration account doesn't really tell us what secures the value of a demonstrative in

\footnotetext{
2 I actually don't want the demonstration account to entail that demonstratives refer since I argue that simple and complex demonstratives are not referring expressions in King (2001), and I want the demonstration account to be consistent with my semantics for simple and complex demonstratives. The demonstration account holds only that the supplementation required by demonstratives, by means of which they acquire values in context, is a demonstration.
} 
context in such cases. Further, I am skeptical about the possibility of formulating a notion of demonstration that is general enough to capture all the cases discussed so far, while excluding cases in which even the demonstration theorist will want to say that there was no demonstration.

A second difficulty, noted by Kaplan (1978), is that in many cases a demonstration will be vague in the sense that there is not a unique thing clearly being demonstrated. An example would be a wave of the hand in the general direction of a child, a bike and a surfboard as I utter 'That is for big waves.' Here it does not seem as though the demonstration alone secured a value for the demonstrative, contrary to what the demonstration account claims.

A final difficulty, again pointed out by Kaplan (1978), is that even if I focus my pointing with laser-like precision on my friend Dan and say 'He is a real estate agent', I am pointing not only at Dan, but at his shirt, his jacket, perhaps a button, etc. So here again, my demonstration-the pointing-does not seem as though it alone secures a value for the demonstrative in context.

As is well known, Kaplan changed his mind about what secures a value for a demonstrative in a context. In Kaplan (1989), he claimed that "at least in the case of perceptual demonstratives" what he called the "directing intention" (he also calls it the "perceptual intention" (1989:583)) of the speaker fixes the value of the demonstrative. Presumably, by "perceptual demonstratives," Kaplan means those that are used to talk about something the speaker is perceiving. The idea, then, is that when a speaker is perceiving an object and forms the intention to talk about it by means of a demonstrative, the value of the demonstrative the speaker produces in such a case is the object the speaker intends to talk about. Call this metasemantics the intention account.

The intention account has a number of difficulties. One problem with evaluating the account is that nothing has been said about how the values of non-perceptual demonstratives are secured in context (see Reimer 1991). But let's just waive this problem for the moment. For the intention account has a more serious difficulty: the intention account seems very strained in cases in which a speaker has the relevant intention but mounts either a poor demonstration or no demonstration. For example, suppose I am at the San Clemente Ocean Festival ("The greatest show on surf!") standing on the pier looking north. Thousands of people are in sight. I fix my attention on a competitor in the mile swim off in the distance getting ready for the event and, intending to talk about her and gesturing vaguely to the north, say 'She looks like a strong swimmer.' You, of course, have no idea whom I am talking about. It seems quite implausible in such a case to say that I succeeded in securing the woman in question as the value of my demonstrative simply because I was perceiving her, and intending to talk about her. Or consider Reimer's (1991) example of two people in a park filled with dogs, one of which the speaker recognizes as her dog Fido. Focusing on Fido and intending to talk about him, she says 'That dog is Fido.' without producing any sort of demonstration (no pointing, nodding, glancing, etc.) due to a sudden and momentary paralysis. Again, it does not seem as though the speaker succeeds in securing Fido as 
the value of her demonstrative in such a case. But she should have if the intention account were correct.

The difficulties noted with the intention and demonstration accounts have inclined some to combine them. Kaplan (1978) suggested such a view. Motivated in part by the second and third difficulties with the demonstration account discussed above, Kaplan suggests allowing the intended demonstratum to play a role in securing the value of a demonstrative in context "within limits." Kaplan doesn't make clear exactly what those limits are. But it is clear that he wants to allow speaker intentions to play a role in securing the value of a demonstrative in context in cases where the demonstration mounted is too vague to do the job itself (e.g. I wave my hand in the general direction of the intended object, where there are other objects in the vicinity). He also wants to invoke intentions to make it the case that when I say 'That is a nice dog, pointing at Fido, his coat and a flea on his coat, it is Fido who gets to be the value of my demonstrative in virtue of my intention to talk about him and not his coat or the flea. Call the metasemantics that allows demonstrations together with intentions (limitedly) to secure the value of a demonstrative in context the hybrid account.

The hybrid account in effect inherits its difficulties from the demonstration and intention accounts that it combines. First, like any account that invokes demonstrations as an important part of the story as to how demonstratives secure values in contexts, the hybrid account needs to address cases of the sort mentioned earlier where it just isn't clear what the demonstration is. That is, the account needs a theory of demonstrations; and as I suggested above, there is reason to be skeptical that a workable theory is forthcoming. Second, like the intention account, the hybrid account seems to predict that speakers secure values for uses of demonstratives in certain cases in which it seems implausible that they do. As we saw in discussing the intention account, these are cases in which speakers have the relevant intentions and either mount a poor demonstration or no demonstration. (Recall the example in which I am at the San Clemente Ocean Festival looking north, with swarms of people in sight; and Reimer's (1991) example of two people in a park filled with dogs, one of whom the speaker recognizes as her dog Fido. ${ }^{3}$ ) Again, it does not seem as though the speaker succeeds in securing a semantic value for her demonstrative in such cases.

Reflection on how and why the three metasemantics for demonstratives I've been arguing against are flawed suggests an alternative view. The view that the demonstration alone secures values for demonstratives was seen to be inadequate partly because speakers often succeed in securing a value for a demonstrative even in cases in which their demonstrations are "unclear", and so cannot by themselves secure a unique value (e.g. a vague gesture in the direction of a number of things); and even if a demonstration is perfectly precise, it typically picks out more than one thing (a dog, its

3 Of course, a version of the hybrid account that requires a use of a demonstrative to be accompanied by a demonstration would not have trouble with this last case. In fact, I believe that Kaplan (1978) intended the hybrid account to be understood in this way. 
coat, a flea, etc.). So something more or different is required. Speaker intentions, with or without demonstrations, were seen to be inadequate as well because the resulting view predicts that speakers secure values for demonstratives in cases in which they intuitively do not.

Thinking about these latter cases suggests that the theories we have looked at err in not requiring the speaker to do enough to secure a value for her demonstrative. In the cases where the intention and hybrid accounts incorrectly predict that speakers secure values for demonstratives, what drives the intuition that they really have not is that their hearers don't seem to have any way of knowing what the relevant values are. Intuitively, the speaker failed to discharge her responsibility to be understandable. This suggests that we should make it a requirement on securing a value for a demonstrative in context that the speaker has discharged this responsibility and has made her hearer able to determine what that value is. However, we don't want to require that the hearer in fact figure out what the relevant value is. That would be too strong. If my hearer is inattentive, incompetent, or simply ignoring me, that should not by itself prevent me from securing a value for my demonstrative. So I suggest we say that the semantic value of a use of a demonstrative $d$ in a context $c$ is that object $o$ that meets the following two conditions: (1) the speaker intends o to be the value of $d$ in c; and (2) a competent, attentive, reasonable hearer who knows the common ground of the conversation at the time of utterance would know that the speaker intends $o$ to be the value of $d$ in $c^{4,5}$ We can abbreviate this by saying that an object o is the semantic value of an occurrence of a demonstrative in context just in case the speaker intends o to be the value and the speaker successfully reveals her intention. ${ }^{6}$ I'll call this metasemantics for demonstratives the coordination account. ${ }^{7,8}$

\footnotetext{
${ }^{4}$ I intend this in such a way that a single object must meet each of the two conditions (and not in such a way that a single object meets both conditions, but e.g. more than one object meets one of the conditions). Further, condition (2) talks of the common ground of the conversation at the time of utterance and so presupposes that there is a unique common ground of the conversation at the time of utterance. This means that the coordination account as sketched presupposes that the context is not defective (i.e. that the presuppositions of the conversational participants are the same (or at least close enough to being the same)).

5 The requirement in condition (2) that an idealized hearer knows that o is the object the speaker intends to be the value of her use of a demonstrative is designed to deal with cases in which the speaker intends $o$ and an idealized hearer would "accidentally" take the speaker to intend o. Josep Macia asks us to suppose that I point to a picture of Ernie and say 'He is smart.' Unbeknownst to me, the frame holding the picture is two-sided and there happens to be a picture of Ernie on the side I cannot see. Because of the way I am situated with respect to the frame and my audience, a reasonable, attentive, competent speaker who knows the common ground of the conversation would take me to intend to be pointing at the picture of Ernie I am unaware of. In such a case I intend Ernie to be the semantic value of 'He' and an idealized hearer would take me to intend Ernie. But such a hearer would not know I intend Ernie and so condition (2) is not satisfied here. Hence Ernie is not the semantic value of my demonstrative in such a case on the coordination account. Thanks to Josep Macia and Jason Stanley for discussion.

${ }^{6}$ Note that a speaker can successfully reveal her intention even though her hearer failed to figure out what she intended. The hearer could be inattentive, incompetent, etc.

7 See King (2012) for ways in which we might want to complicate the coordination account.

8 Stephen Neale (2004) uses two conditions similar to those in the coordination account to define a notion of speaker reference (80). Though the conditions Neale uses are similar to those in the coordination
} 
Note that on this view, demonstratives do not require an accompanying demonstration. Indeed, the coordination account sees demonstrations in a new light: a demonstration is simply a means of revealing a speaker's intention and so insuring that condition (2) above is met. But a speaker need not reveal his intentions this way. There are many other ways of revealing one's intention and so meeting condition (2). If we both witness a loud explosion and I say 'That was earshattering', intending to talk about the noise, condition (2) is bound to be satsified in the absence of a demonstration. And so on the coordination account, the noise is the value of my demonstrative. This kind of case highlights an advantage of the present view over views on which demonstratives must be associated with demonstrations. As we saw, such views must give an account of what the demonstration is in cases in which it is not at all clear what the demonstration is or even whether there was one, including the case just mentioned as well as those discussed earlier. By contrast, the coordination account can simply deny that there are demonstrations in such cases. As long as conditions (1) and (2) are each satisfied by the same object in such cases, a value will be secured despite the lack of a demonstration.

The coordination account avoids the other problems with the demonstration account. Vague demonstrations or demonstrations that by themselves don't determine a unique object are no problem for the coordination account since it doesn't claim that demonstrations alone secure values for demonstratives. Again, on the coordination account all demonstrations ever do when they accompany demonstratives is to help with the satisfaction of condition (2) above. But other things may help too.

The coordination account avoids the problems with the intention account as well. Recall that cases in which speakers have the relevant intentions but mount poor or no demonstrations caused trouble for this account since it predicts that speakers secure values for their demonstratives, whereas intuitively they do not. In cases of this sort, some of which were described above, the coordination account says that the demonstratives will not have values since condition (2) above will not be satisfied. Finally, the coordination account avoids the problems of the hybrid account, since the problems with that account were problems had by the demonstration and intention

account, it is important to see how different our views actually are. First, I reject the account of speaker reference Neale characterizes using conditions similar to those used in characterizing the coordination account. I favor an account of speaker reference on which the speaker's reference in using an expression is the object the speaker "intends to talk about" by means of the expression. I don't believe anything about hearers, idealized or otherwise, should be brought in here. Second, the coordination account is an account of the semantic value of a use of an expression in a context. Neale makes clear that he rejects any notion of the semantic value of a use of an expression in a context "unless such talk is taken to be straightforwardly translatable into talk about things that speakers are doing" (80). The way I understand the coordination account, it is a robust account of the semantic value of the use of an expression in a context that won't be straightforwardly translatable into talk about what speakers are doing. Hence, Neale would reject it. In short, Neale's account of speaker reference and the coordination account are logically independent of each other: neither entails the other. I reject his account of speaker reference and he rejects my account (and any robust account) of the semantic value of the use of an expression in a context. Thanks to Stephen Neale for helpful discussion. 
accounts; and we have seen that the coordination account avoids the problems with those views.

I think of the fact that a speaker intends an object to be the value of an occurrence of a demonstrative and the fact that a competent, attentive, reasonable hearer who knows the common ground of the conversation would take the speaker to intend that a certain object be its value to be objective features of a context of utterance. Call the former the speaker fact and the latter the hearer fact. A context is appropriate for a sentence containing demonstratives if each occurrence of a demonstrative in it is associated with a speaker fact and a hearer fact and these facts "involve" the same object (i.e. the intended object in the speaker fact is the object that would be taken to be intended in the hearer fact). For a given occurrence of a demonstrative in an appropriate context, call this latter object the coordinated object. Then I view the meaning of a demonstrative as a function that maps an appropriate context to the coordinated object. I take the latter to be the semantic value of the occurrence of the demonstrative in the context. ${ }^{9}$ Finally, I take the lexical meanings of demonstratives to require that a use of a demonstrative be supplemented by a speaker's intention that is recognizble by an ideal hearer in just the way that the demonstration account held that the lexical meanings of demonstratives require that a use be supplemented by a demonstration. ${ }^{10}$ Though demonstratives share this feature of their lexical meanings, different demonstratives have other, different features of their lexical meanings (e.g. 'he' has as part of its lexical meaning that its value in a context must be male, but 'it' does not; 'that' has as part of its meaning that the thing it is used to talk about is distal, 'this' does not, etc.).

My defense of the coordination account has amounted to claiming that it gets the intuitively correct results in a variety of cases. That is, it predicts that speakers secure values for their demonstratives in cases in which that verdict seems intuitively correct; and it predicts that speakers fail to secure values for their demonstratives in cases in which that verdict seems intuitively correct. However, there are other considerations in favor of the coordination account as well. ${ }^{11}$

I mentioned above that one advantage the coordination account enjoys over accounts that require demonstratives to be accompanied by demonstrations is that accounts of the latter sort must tell some story about what the demonstration is in cases in which speakers seem to successfully secure values for their demonstratives

9 Or at any rate, this is so for demonstratives that refer. Recall that I don't take simple or complex demonstratives to be referring expressions, so the story is a bit different for them.

10 We can now make more precise the sense in which supplementives require supplementation in context to have semantic values in context in a way that pure indexicals do not. Pure indexicals have meanings that are functions defined on all contexts (since all contexts have speakers, times and places), whereas the meanings of supplementives are defined only on appropriate contexts. This means that a speaker using a supplementive must do something (form the relevant recognizable intention) to insure that the context is of a sort that the supplementive's meaning is defined on. This latter is the required supplementation. Thanks to Alexi Burgess for helpful comments here.

11 Still other virtues of the coordination account are discussed in King (2012). 
despite not appearing to mount demonstrations in any obvious sense. The coordination account can simply deny that there are any demonstrations in such cases and claim that in these cases speakers reveal their intentions by other means.

A related advantage of the coordination account is that there is no puzzle at all about cases of so-called deferred reference: cases in which one in some sense indicates one thing while securing some distinct thing as the value of the demonstrative. Suppose we are in a graduate seminar. It is common ground that a participant, Glenn, is skiing at Mammoth today and so couldn't attend the seminar. It is also common ground that he always sits in a now empty chair to my right. Intending to say something about Glenn, I point at the empty chair and say 'I bet he is having fun right now.' Since I intend Glenn to be the value of my demonstrative and a competent, attentive, reasonable hearer who knows the common ground of our conversation would take him to be the object that I intend to be the value, the coordination account predicts that he is the value of my use of the demonstrative. What cases of so-called deferred reference show is that one can successfully reveal one's intention to have o be the value of a use of a demonstrative by demonstrating some object other than o. This is hardly surprising given that speakers can even successfully reveal such an intention by demonstrating nothing at all, as we have seen.

We now turn to the question of whether the coordination account can be applied to the supplementives I mentioned at the outset. I am going argue that it clearly can be in some cases and will discuss what would be required to apply it to others, concentrating on the case of gradable adjectives.

Let's begin with relational expressions that take implicit arguments. In normal uses of 'Cindy is ready.' it seems to me quite plausible that the coordination account gives the correct view of how the implicit argument is supplied in context. For, first, it seems plausible that speakers do intend specific implicit arguments when they felicitously utter sentences like 'Cindy is ready.' Second, it seems plausible that if they lack such intentions or if they fail to reveal their intentions, they will have failed to secure an implicit argument. Third, it seems plausible that if the speaker does intend a certain implicit argument and an idealized hearer who knows the common ground of the conversation would see that the speaker intended it, then it is the implicit argument supplied in context. In other words, speakers have the sorts of intentions the coordination account appeals to in using expressions that take implicit arguments. Further, when the conditions the coordination account specifies are met, it seems plausible that an implicit argument has been secured as a semantic value in context; and when they are not met, it seems plausible that no implicit argument has been secured. That is a good reason for thinking the coordination account applies here.

Exactly similar remarks apply in the case of quantifier domains and possessives. In all these cases, then, the coordination account looks like a promising metasemantics for the supplementives in question.

However, there is a phenomenon involving these expressions that might make some doubt my claim that the coordination account provides the correct metasemantics for 
them and that will make us look at the coordination account somewhat differently. Consider quantifier domains as an example. The idea here will be that when I say 'Every student passed', there will be some property that I intend to further restrict the domain and that an idealized hearer who knows the common ground of the conversation would take me to intend. This property is then what does the further restricting. ${ }^{12}$ In many cases things work this way and the coordination account applies neatly. However, as many have pointed out, in some cases of uttering quantified sentences, speakers probably have not formed an intention that picks out a single property to further restrict the domain of a given quantifier. For example, I say 'All the beer is in the fridge.' and there is a range of properties-being just bought by us, being just carried in from the car by us and so on-such that it isn't clear that I intended any one of them or that an idealized hearer who knew the common ground of the conversation would have taken me to intend any one of them. But then it may look like the coordination account doesn't apply here.

I am not sure exactly how to think of such cases theoretically. But even in this case, I think I did have an intention that determined a certain range of properties. The presence of such intentions is suggested by accompanying dispositions to respond affirmatively or negatively when asked completions of the following: 'Did you mean the beer that...?' Similarly, an idealized hearer who knew the common ground of the conversation would have taken me to have intended a certain range of properties. One way to think of this theoretically is that I have in some sense put a bunch of propositions in play-one corresponding to each property in the range-by intending a certain range of properties and having revealed my intention..$^{13}$ So here it seems to me the coordination account applies in sort of a 'loosened' or generalized way. It appears that the reason for allowing such looseness in this case is that conversational purposes do not require me to use any particular property to further restrict the quantification as long as I get you to attend to the beer I intend to talk about. What seems to me to be a closely related phenomenon will be discussed further below, where we will see that the phenomenon appears to arise with virtually all supplementives (though perhaps it arises more frequently with some supplementives than others).

This leaves us with gradable adjectives, modals and conditionals. I will only address the case of gradable adjectives here but I think that modals, conditionals and other supplementives raise similar issues. I hope to show what kinds of moves would have to be made if the coordination account were to apply to gradable adjectives as well as some other cases.

\footnotetext{
12 I am being deliberately a bit vague here to remain neutral on the question of how the details of doman restriction work (I am actually doing that with all the cases I am looking at except demonstratives). I am, however, sympathetic to the sort of view Stanley and Szabo (2000) defend.

13 Gillies and von Fintel (2011) have the notion of putting multiple propositions in play in uttering a sentence containing an epistemic modal.
} 
Michael Glanzberg (2012) gives several arguments that gradable adjectives are not governed by what he calls a direct metasemantics, though he does take other supplementives, specifically demonstratives and what he calls thematic parameters, to be governed by one. Glanzberg takes a direct metasemantics for a supplementive to be one where its semantic value in context is determined by the speaker's intentions. That is, Glanzberg's direct metasemantics is what I called the intention account. I have argued that the coordination account is a better metasemantics for demonstratives than the intention account; and Glanzberg's arguments, if they worked, would show that the coordination account is not the right metasemantics for gradable adjectives. So henceforth in discussing Glanzberg's account, I will just take his direct metasemantics to be the coordination account. Thus, I will reconstrue Glanzberg as allowing that the coordination account applies to demonstratives and thematic parameters, which include relational expressions taking implicit arguments, and arguing that the coordination account does not give the correct metasemantics for gradable adjectives.

Because it will be relevant to our discussion, I must sketch the semantics for gradable adjectives that Glanzberg assumes, which is due to Christopher Kennedy (2007). We will only be concerned with the positive form of gradable adjectives. On Kennedy's view, adjectives denote measure functions: functions that map individuals to degrees (type $<\mathrm{e}, \mathrm{d}>$ ). These degrees are totally ordered with respect to some dimension given by the adjectives meaning, yielding a scale. Adjectives combine with degree morphology resulting in something that denotes a property of individuals. In the positive form ('is tall'), the degree morpheme is a null morpheme pos. Hence, syntactically, the adjective with degree morpheme looks as follows:

(1) [DegP $[[$ Degpos $][$ APtall $]]]$

The semantics for pos is: $\|p o s \mid\|^{\mathcal{C}}=\lambda g \lambda x . g(x)>s(g) . s$ is determined in context and will be a function from adjective meanings to degrees on the scale appropriate to the adjective's meaning ( $g$ ranges over adjective meanings; and $x$ ranges over individuals). Thus $\|\left[\right.$ DegP $\left[[\right.$ Degpos $]\left[{ }_{\mathrm{AP}}\right.$ tall $\left.\left.]\right]\right] \|^{\mathrm{c}}=\lambda x \cdot \operatorname{tall}(\mathrm{x})>s($ tall $) .{ }^{14}$ An individual o has this property just in case the height tall assigns to $o$ is greater than the height the contextually determined function $s$ assigns to tall. ${ }^{15}$

The contextual sensitivity here is a result of the fact that the function $s$ from adjective meanings to degrees on the scale given by tall must be determined in context. I take it that Kennedy's view is that the meaning of pos is such as to require saturation in context by a function from adjective meanings to degrees. On this way of understanding Kennedy, pos is the supplementive here. Thus if my coordination account applies here, and if $s$ is determined in context, the speaker must intend that $s$ be the value assigned to pos in the context; and an indealized hearer who knows the common ground of the conversation must see that the speaker intends $s$ to be the

14 tall is the semantic value of 'tall'.

15 Here I am identifying people's heights with degrees on the height scale. 
value. Glanzberg complains that this could not be so, because ordinary speakers and hearers do not have intentions or thoughts about functions from adjective meanings to degrees on the relevant scale.

I think Glanzberg is right that ordinary speakers do not have intentions that have functions from adjective meanings to degrees as their objects. Indeed, Glanzberg raises an important point here: if the coordination account is to apply to a given supplementive, the values assigned to it in context must be such that it is plausible that ordinary speakers have intentions regarding them. Hence, exotic, highly abstract or mathematically sophisticated entities are ruled out as semantic values of a supplementive in the mouths of ordinary speakers if the coordination account is the correct metasemantics for that supplementive. ${ }^{16}$ The question this raises for the coordination account is whether there is a plausible view along the lines of Kennedy's (2007) on which the entity assigned to pos in context is something that can be determined by the intentions of ordinary speakers, unlike the function $s$ from adjective meanings to degrees.

Before addressing this question, however, I want to distinguish the concern I am discussing here from another that it could be confused with. I have heard people claim that a certain semantic theory can't be correct because the context independent semantic values it assigns to expressions are 'too complicated' in some sense (typically, formally/mathematically). That is not the worry being addressed here. The claim is that, if the semantic value secured by a supplementive in context is so because the speaker intended it to be the value, and an idealized hearer who knows the common ground of the conversation would see that the speaker intended the relevant value, then the value had better be something ordinary speakers intend in using the expression in question. Certain sorts of "formally sophisticated" values (e.g. functions from adjective meanings to degrees) don't seem to satisfy this condition. But this has no import at all as far as I can see for the question of whether a semantics that assigns "formally sophisticated" context independent semantic values to expressions is to be faulted for doing so. ${ }^{17}$

To return to the main theme, instead of the semantics for pos proposed by Kennedy above, I propose the following: $\|p o s\|^{\mathrm{c}}=\lambda g \lambda x \cdot g(x)>d_{\mathrm{c}}$, where $d_{\mathrm{c}}$ is a degree on a scale determined in context. In turn, $\|[$ DegP $[[$ Degpos $][$ APtall $]]] \|^{c}=\lambda x \cdot \operatorname{tall}(\mathrm{x})>$ $h_{c} \cdot{ }^{18}$ I claim that the height $h_{c}$ is determined in context in accordance with the

16 The restriction to ordinary speakers here is important since formal sophisticates can have a highly abstract formal object be the semantic value of e.g. 'that' in a context. Further, even the claim about ordinary speakers is qualified below.

17 Thanks to Jason Stanley for helpful discussion.

18 One of the reasons Kennedy (2007) favored using the function $s$ from adjective meanings to degrees in the semantics of pos is that he thought the meaning of an adjective played some role in determining the degree that something had to be above or below to have the adjective correctly apply. My thought is that the meaning of the adjective can still play a role here by constraining what a competent speaker intends in using the adjective in something like the way the meaning of 'he' constrains what a speaker can reasonably intend (males!) in using 'he' and by constraining what an idealized hearer who knows the common ground of the conversation would take the speaker to intend. I discuss this further below. 
coordination account. Suppose I am in a context $\mathrm{c}$ where I have a pretty clear intention to count people six foot two and up as tall, and an idealized hearer who knew the common ground of the conversation would see that I intended this. Then $h_{c}$ is six foot two.

The account works here because we have identified heights with degrees on a scale, and assumed speakers can have intentions about 'cut off' heights for 'tall' in contexts. So the speaker's intentions determine a height degree very directly by being intentions that have heights (numbers) as their objects. But what about other gradable adjectives where speakers will not have intentions with numbers as their objects in using them, as with, say, 'smart'? Here I think we are going to have to say that the speaker has an intention whose object determines a degree, with the result that the relation between the intention and the degree is less direct than the relation between an intention and the semantic value of a demonstrative or the semantic value of pos when combined with 'tall'. Suppose that in using 'smart' I intend that a certain kind of person as regards intelligence provides the cutoff for being smart. People of that kind as regards intelligence and anyone smarter count as smart. ${ }^{19}$ Call the kind of person I intend here the object of my intention. Suppose an idealized hearer who knows the common ground of the conversation would recognize my intention. I suspect when colleagues and I discuss philosophers we think are smart this is the case. Since the kind of person I intend has a degree of smartness, the object of my intention, and an idealized hearer's recognition of my intention, determine a degree of smartness in context. Here the connection between the intention and the degree will be a little more indirect than in cases where numbers just are the objects of my intention.

It is worth highlighting the two strategies that were employed in trying to respond to Glanzberg's argument that gradable adjectives are not governed by the coordination account. First, we changed the alleged semantic value assigned in context from something that it did not seem could be the object of the intentions of ordinary speakers in using gradable adjectives to something that it seems could be. In the case of 'tall' it was specific heights that are then degrees on a scale of tallness; in the case of 'smart' it was a certain kind of person as regards intelligence. Second, in the case of gradable adjectives like 'smart' where it is implausible that speakers have numbers as the objects of their intentions, we made the relation between the intentions of the speaker and the semantic value assigned in context more indirect than it is in the case of demonstratives or gradable adjectives like 'tall'.

I emphasize these points because I suspect other cases will require similar strategies. Consider a case where the leading semantic theory of a given supplementive has it taking on semantic values in context that don't appear to be the sorts of things that can be the objects of the intentions of ordinary speakers. Call such a case a recalcitrant

19 Evidence that we have kinds of people in mind when using adjectives like 'smart' is given by the fact that if asked what I mean by 'smart' in a given case, I often start to articulate what kind of person as regards intelligence I have in mind: 'you know, she gets points quickly, makes good critical remarks, ...'. 
case. Then the current strategy for having the coordination account handle recalcitrant cases is: make sure the objects of speakers' intentions really are things they can have intentions about and that hearers can have beliefs about (e.g. in the case of 'tall', we swapped out $s$ for $h_{c}$ ). Call these the objects of the intentions. Then make sure the objects of intentions determine the semantic values assigned to the supplementives in context in some manner or other. I leave open the question of what other strategies might be available for the coordination account in dealing with recalcitrant cases. One thing to think about here is whether positing different sorts of speaker intentions would help with certain cases. This would require thinking a lot more than I have about the nature of intentions generally. ${ }^{20}$

Let me now turn to why Glanzberg's metasemantics for pos is in certain ways unattractive. Actually, Glanzberg is up front about the fact that he really doesn't have a full blown account of the metasemantics for pos. He does say that a lot of things are involved and that it will be messy. Glanzberg (2007) writes:

I have argued for contextual parameters which require highly indirect metasemantics. What fixes their values will be complicated combinations of such factors as what is salient in the environment, speakers' intentions, hearers' intentions, coordinating intentions, linguistic meaning, general principles governing context, discourse structure, etc. From these resources, values will have to be computed. (2007: 25)

\section{He also says:}

A contextual parameter with an indirect metasemantics must be set by the various pieces of information context provides, but context does not simply hand us a value for such a parameter, nor does it hand us a uniform rule for computing the value from a specific piece of contextual information. Rather, a range of contextual information and computational rules must be taken into account and weighed in working out the value from context. (Glanzberg 2007: 19)

So Glanzberg's indirect metasemantics for certain parameters-again, Glanzberg's term for supplementives-is going to be extremely messy, involving as it does a tremendous number of factors. But Glanzberg also thinks there is no uniform rule by means of which these factors are weighed. Because of this, Glanzberg admits that speakers and hearers often will be ignorant of or mistaken about what value has been assigned to the supplementive in context (2007: $26 \mathrm{fn} 22$ ). In turn this means that the value that has been assigned to the supplementive plays no real role in communication in such cases. Not much use having a value assigned to a supplementive if it plays no role in communication! Further, I find it hard to believe that we would have evolved a metasemantics for some supplementives that is this messy and non-uniform. What would be the point, if the result was that we were often in the dark about what the metasemantics delivers?

20 I endorse some version of the planning theory of intentions of the sort Bratman defends but I haven't thought much about the details in the present case. Another thing to think about is the idea that certain things are more eligible than others to be the objects of intentions and how that would play out here. 
Let's turn to a second argument that Glanzberg gives against the view that gradable adjectives are governed by the coordination account. In the case of thematic parameters and demonstratives, which according to Glanzberg are governed by a direct metasemantics like the coordination account, Glanzberg thinks that the presence of the relevant intention is attested to by the fact that we can query what the speaker intended and expect a sharp reply. Consider expressions that allow an implicit argument, which Glanzberg takes to involve a thematic parameter, and demonstratives:

I. A: John won.

B: What did John win?

A: The chess match.

II. A: She is smart.

B: Who?

A: Her/Cindy.

But in the case of gradable adjectives, Glanzberg claims, things are different. First, there is no natural way to query the alleged intended standard, for example, for being rich. Second, the response won't be to offer a standard and is likely to be unhelpful ('You know, rich' or 'Well, kind of rich'). These alleged facts, Glanzberg thinks, show that the relevant intention is simply not present.

Recall that on the view I am defending, in using gradable adjectives, speakers have intentions regarding the "cutoff" for being tall or rich and these intentions, when they would be recognized by idealized hearers, directly or indirectly determine degrees on the relevant scales. It seems to me that in many cases, speakers clearly do have such intentions in using gradable adjectives. When Obama and his cabinet are discussing why they won't extend tax cuts for the rich, and Obama includes himself as rich, he very clearly intends that the cutoff point for being rich is making more than $\$ 250,000$ per year and an idealized hearer would recognize his intention. \$250,000 can then just be taken to be the degree on the scale above which people count as rich in this context. Contrary to what Glanzberg claims, we can query someone about his intention in this sort of case. After hearing Obama and not being attuned to his position on the Bush tax cuts, I can query his intention by asking 'How rich?' Obama would, of course, reply sharply by saying 'anyone who makes over $\$ 250,000$ per year'. Similar remarks apply to a case of US swim coaches at the Olympic trials saying 'Missy was fast in the 100 back this morning.' Again here, they would have specific intentions that determine degrees on the relevant scale (in this case, swim times), and idealized hearers would recognize this. So contrary to what Glanzberg suggests, I think it is clear that in many cases speakers will have intentions in using gradable adjectives that determine degrees on the relevant scales, as shown by the fact that they can be queried about their intentions and they can provide sharp replies about the relevant standard. 
However, I think there is an element of truth to Glanzberg's concern that in some cases speakers do not have intentions determining specific degrees in using gradable adjectives, though I understand what is going on in such cases differently from Glanzberg. This is related to the phenomenon I discussed above concerning quantifier domains. It seems to me that speakers often use gradable adjectives in a "loose way", where they don't have intentions that are specific enough to determine a unique degree. I suspect that this is due to conversational purposes being different in such cases than they are in the cases discussed above where specific intentions are present. When Obama is talking about not extending tax cuts for the rich, conversational purposes dictate that we have a very specific idea about who counts as rich. After all, we are going to propose allowing taxes to rise for a group of people and claim that this is a good idea. As such, we had better be clear about who is rich. Similarly, the swim coaches are interested in exchanging information about swimming speed in a sport where elite races are often decided by hundredths of seconds. But in normal conversations in which only a low degree of precision is required or where the conversation is quite casual, there is just no need for speakers to have very specific intentions about who counts as rich, fast, or tall.

Of course, even in these cases speakers will have intentions that rule some things out. When I told my wife the ocean was cold the other day, I certainly didn't have an intention that a water temperature of $\mathrm{n}$ degrees Fahrenheit or below counts as being cold. But I certainly intended, for example, to rule out 70 degrees as being cold. It is natural to think that in such cases speakers' intentions determine a range of degrees on the relevant scales. As in the case of quantifier domain restriction, my dispositions to respond to completions of "Did you mean to count... degrees as cold?' attest to the presence of such an intention. And as in the case of quantifier domain restriction, I won't try to say how exactly to treat this phenomenon theoretically. Again, perhaps we want to say that in some sense speakers are putting in play a bunch of propositions involving the degrees in the range determined by my intention. Or perhaps we should spell things out in some other way. The point is that in these cases, where Glanzberg sees no speaker's intention that can play a role in determining degrees on a scale, I see an intention that determines a range of degrees rather than a specific degree.

I have claimed that depending on conversational purposes, speakers' intentions sometimes determine a degree on a scale and sometimes merely determine a range of degrees. This amounts to claiming that the supplementive in gradable adjective constructions sometimes gets assigned a unique semantic value in context and sometimes gets associated with only a range of values (or perhaps we should say that the value is the range). We saw above that a similar phenomenon occurs in the case of quantifier domain restriction. It is important to see that this happens with what Glanzberg calls thematic parameters and demonstratives as well, where, again, Glanzberg agrees that a direct metasemantics like the coordination account is the correct metasemantics. But then by Glanzbergs own lights, these phenomena cannot preclude a direct metasemantics for the relevant expressions. Suppose I am surfing at Lost Winds beach. South 
of me are a bunch of other surfers. I keep seeing different surfers from the pack getting incredible waves. I comment to my buddy nodding to the south 'Those guys are good.' It seems doubtful that my intentions pick out a unique group of guys and it seems doubtful that my buddy takes them to. I think the reason is that for the purposes of our conversation, all that I am trying to or need to convey is that there are numerous good surfers among the group to the south. So here my intentions, and the fact that they would be recognized by an idealized hearer, determine merely a range of groups, and hence potential semantic values, for the demonstrative. ${ }^{21}$

Similarly, suppose Cindy has a troubled relationship with her mother, who is thoughtless and bitter. Cindy and I visit her mother one day and the mother is clearly in a foul mood. She immediately begins to berate Cindy about her not having a better job, not being married and so on. She also adjusts Cindy's clothing and hair and offers her lipstick and other makeup, clearly implying that she needs more makeup and that her clothes are inappropriate. All the while she is swigging whisky and smoking. At some point Cindy says 'I've had enough.' and walks out the door. Did Cindy's intentions at the time of utterance determine a single thing that she has had enough of? It seems clear that this need not be the case. It seems likely that she intended a range of things that she has had enough of and an idealized hearer would recognize that. So again we get recognizable intentions determining a range of potential semantic values here.

We live in New York and are getting married in San Clemente, California. We are discussing whether to have a New York firm cater our wedding or whether to have some firm near where the wedding is do it. I say 'Having a caterer from New York would be a lot of hassle. Let's just go with a local firm.' In uttering this did my intention determine what the firm had to be local to? Again, it seems likely that there is a range of locations determined by my intentions: San Clemente; the area consisting of Dana Point to San Clemente; Southern Orange County, etc. So again my recognizable intentions determine a range of potential semantic values.

I think we can even get something like this phenomenon with singular demonstratives and pronouns. Here are three cases. Annie, Thony, Mary and I are in a restaurant in Barcelona eating tapas. We have five on the table that we are eagerly sampling and more are on the way. Annie says 'This is so good.' Must Annie have intended some one thing as the semantic value of 'This' and would an idealized hearer who knows the common ground of the conversation recognize that she did? It seems that there are a range of things that Annie's intentions leave open as candidates to be the semantic value of 'This' here. ${ }^{22} \mathrm{~A}$ second case: suppose we are watching an air race with

\footnotetext{
21 This example was inspired by a similar example Thony Gillies suggested to me to make a somewhat different point.

22 Thanks to Annie Papreck King for the example. I suspect that things in the range include the meal we are now having, the food we are currently eating, four of the tapas we are currently eating (Annie thought the pimientos de patron were a bit oily), and so on.
} 
binoculars. Planes are copiloted with each pilot having equal time piloting the plane. We notice smoke coming from one of the planes and I say 'He's in trouble.' Again here, must I have intended one of the pilots or even the plane itself as the semantic value? It seems not and it seems that both pilots and the plane are in the range of objects determined by my intentions and an idealized hearer would recognize this. ${ }^{23}$ Third example (real life case!). Annie has been trying to download some printer drivers from the HP website. She keeps getting an error message from the site. We tinker and make various changes and she tries it again. I yell down to her from upstairs 'Did it give you an error message?' Did I intend for a unique thing to be the semantic value of 'it'? No, I didn't. For my intention didn't distinguish between Annie's computer, its operating system, the HP website, and so on. Again, it appears that my intentions determined only a range of possible semantic values here and Annie no doubt recognized that.

Glanzberg's final argument that the supplementive involved with gradable adjectives isn't governed by the coordination account metasemantics concerns a phenomenon that, following Richard (2004), he calls accommodation and negotiation. With gradable adjectives, Glanzberg thinks, sometimes we accommodate what we see to be a speaker's view about who counts as rich or tall and allow this to be entered on the conversational record. However, when different speakers have different views about this, sometimes the cutoff point is negotiated. Glanzberg (2007: 27) claims that a direct metasemantics like the coordination account is not consistent with this accommodation and negotiation and that an indirect metasemantics of the sort he suggests would allow it.

However, I think we do see accommodation and negotiation in cases in which we have direct metasemantics even by Glanzberg's lights. Consider the following case. You are the boss of a large company and I am your next in command. Yesterday you warned a habitually tardy employee, Alan, that he had better be at work before 9 A.M. the next day. The next morning at exactly 9 A.M., we discover that Alan walked through the front door of the company's office building at 8:58 and is now making his way up to his 30 th floor office. At what we know to be exactly 9 A.M. standing in front of Alan's office, I say to you "As instructed, Alan arrived before 9 A.M. and he is on his way to his office now.' Peering into Alan's office you say 'As you can see, Alan hasn't arrived and it is 9 A.M. You must fire him.' It appears that what is going on here is that we are negotiating over the implicit argument for 'arrived'. I want it to be the office building and you want it to be Alan's office. So there does seem to be negotiation over the implicit argument. Of course, you also could have instead accommodated my preferred implicit argument. But though we have accommodation and negotiation over the implicit argument, even Glanzberg thinks that the metasemantics governing such implicit arguments is direct. So the presence of negotiation and accommodation over the value of a supplementive cannot show that it is governed by an indirect

23 Note how strange it would be for you to ask me 'Did you mean one of the pilots or the plane or ...?' 
metasemantics. Hence if this does occur in the case of gradable adjectives, that is consistent with the coordination account being their metasemantics.

Indeed, given what I said earlier, we should expect accommodation and negotiation in the case of gradable adjectives. Accommodation will occur in a case where you recognize my intention that the cutoff point for my use of 'rich' is making n dollars, and have no problem with that. Here the coordination account predicts that $\mathrm{n}$ is the degree of wealth required to be rich in this context. Further, if in using gradable adjectives intentions sometimes only determine a range of degrees due to conversational purposes as I suggested, and if the conversational purposes shift in such a way as to require more precision, and if conversational participants have diverging interests concerning what degree gets selected, we would precisely expect there to be negotiation. Let me hasten to add that I am not claiming that it is only in this sort of case that we would expect negotiation if the coordination account is correct. But it is one kind of case where we would expect it.

Now suppose my responses to Glanzberg are all correct. (Hold that thought!) It is still true that the coordination account works a bit differently in the case of some supplementives. As we saw, at least in the case of some gradable adjectives, the relation between speakers' intentions and the semantic value assigned to pos is more indirect than in the case of demonstratives and relational expressions with implicit arguments. So it may be that Glanzberg can argue that the metasemantics still works somewhat differently in the cases of the two sorts of supplementives he alleges exist. ${ }^{24}$ In any case, as I've said I think he makes a good overall case for the conclusion that is most important to him: there are two importantly different kinds of supplementives. ${ }^{25}$

24 A lot will hinge on what to say about things like quantifier domain restriction, where I have argued that the metasemantics works essentially in the same way as for demonstratives and relational expressions with implicit arguments. That shouldn't be for Glanzberg since the latter are one kind of supplementive for him and the former are another.

${ }^{25}$ I have said that if the coordination account is to apply to gradable adjectives, we are probably going to have to admit it works a bit differently in the case of at least some gradable adjectives (e.g. 'smart') than it does in the case of demonstratives. I also wish to make clear that I think that there are probably important differences in behavior between certain supplementives. For example, I think gradable adjectives are sometimes used to draw people into a conversation about a certain topic. Suppose we are swimmers and have a mutual friend, Amy, who we both used to workout with and who we haven't seen in a while. We were both significantly faster than Amy when we trained together. I say to you: 'I swam with Amy today. Boy she's getting fast.' I may pause here and fully expect that since you won't be sure exactly what standard of fastness I am employing, you will reply with something like 'Fast, really? Amy was pretty slow before. How fast are we talking here?' This is a perfectly good way to get into a discussion about Amy's swimming speed. I don't think there is an analogous phenomenon in the case of demonstratives (I can say 'He's brilliant, you know' not making clear who I intend and fully expecting you to ask whom I am talking about. But this seems a much more marked usage than that of 'fast' above). If the coordination account is to be applied across the board, such differences in behavior will have to be explained in ways that are consistent with there being a single metasemantics for supplementives. One promising avenue is that different supplementives are able to serve different conversational purposes due to e.g. the kinds of lexical meanings they have, the purposes served by the parts of speech they are etc. In the present case, for example, the meaning of 'he' is so thin that it doesn't serve much purpose to use it without doing what is required to secure a semantic value for it. When I use 'fast' without having done so, I at least signal to you that I am going to talk about things' speeds by some standard of speed or other. So a topic has been initiated. 
Earlier I briefly touched on Kennedy's (2007) idea that the meaning of an adjective plays a role in determining the standard associated with the use of that adjective in context. ${ }^{26}$ As we have seen, Glanzberg (2012), with his indirect metasemantics for some supplementives, thinks many features of the context of utterance may go into determining the value of certain supplementives in context. Since many people, including me, find some version of this idea plausible, it is worth noting that the coordination account preserves it. On the one hand, the coordination account claims that the value of a use of a supplementive $s$ in context $c$ is the entity o that satisfies the following two conditions: (i) o is the object the speaker intends to be the semantic value of the s in c; (ii) a reasonable, competent, attentive hearer who knows the common ground of the conversation would know the speaker intended o to be the value of $s$ in c. So there is a sense in which only the intentions of the speaker and what an idealized hearer would know the speaker to intend go into determining the semantic value of a supplementive in context according to the coordination account. However, many, many factors about the context of utterance, including the meanings of the words the speaker is uttering, prior discourse, questions under discussion, etc., constrain what a speaker can reasonably intend to be the value of a use of a demonstrative and determine that an idealized hearer who knows the common ground of the conversation would know what the speaker intends. To take a very simple example, recall the case of Glenn not being in a meeting of the graduate seminar and his empty chair being demonstrated while I say 'He is having fun now.' Had it not been in the common ground that Glenn always sits in that chair and that Glenn is skiing at Mammoth on the day in question, a speaker could not reasonably intend that Glenn be the semantic value of 'He' in this context. Exactly similarly, that a reasonable, competent, attentive hearer who knows the common ground of the conversation would know the speaker intended Glenn in this case is determined in part by the fact that it is in the common ground that Glenn always sits in the relevant seat and that he is at Mammoth today. Since many features of context in this way affect what reasonable speakers can intend in using supplementives and what idealized hearers would know speakers to intend, a large variety of features of context play a role in determining the semantic values of supplementives in context. Hence, what the coordination account says about a wide variety of factors about context playing a role in determining semantic values of supplementives in context differs from Glanzberg's indirect metasemantics only in how the many factors affect the fixing of a semantic value in context. I think this should be enough to placate those who think that a large number of features of contexts of utterance are involved in the determining the semantic values of supplementives in context. For according to the coordination account, they are!

One final point. David Lewis famously thought that mental properties are just very complicated physical properties. But this raises a puzzle for him (Lewis 1994: 297-8).

26 See footnote 18. 
Very complicated physical properties are often such that precisely because of their enormous complexity, they are beyond our ken. However, we can think of and track the physical properties that are mental properties. How? It is because we can sometimes have simple ways of thinking about properties that may be enormously complex. In the case of the physical properties that are mental properties, Lewis thought that we think of them as the properties that bear such and such causal relations to perceptual input, behavioral output and other mental properties. Whether Lewis is right about all this, I'll leave for another time. However, his point plausibly applies here. The property of being intended by the speaker and being recognized to be so by an idealized hearer who knows the common ground is a very complex property. If we tried to say what property it is in terms of discourse structure, question under discussion, salient entities and so on, we probably couldn't do it. However, when we think of the property in terms of being intended by the speaker and recognized to be so by an idealized hearer, we have no trouble thinking about and tracking this very complicated property. This resolves the Lewisian style mystery in the present case. ${ }^{27}$

\section{References}

Gillies, A. and von Fintel, K. (2011). “'Might' Made Right”. In A. Egan and B. Weatherson (eds), Epistemic Modality. Oxford: Oxford University Press, pp. 108-30.

Glanzberg, M. (2007). “Context, Content and Relativism”. Philosophical Studies 136: 1-29.

Glanzberg, M. (2012). "Not All Contextual Parameters Are Alike”. Unpublished ms.

Heck, Jr., R.G. (2014). "Semantics and Context-Dependence: Towards a Strawsonian Account". In A. Burgess and B. Sherman (eds), Metasemantics: New Essays on the Foundations of Meaning. Oxford: Oxford University Press.

Kaplan, D. (1977/1989). "Demonstratives". In J. Almog, J. Perry, and H.K. Wettstein (eds), Themes from Kaplan. New York: Oxford University Press.

Kaplan, D. (1978). "Dthat". Syntax and Semantics 9: 221-43. Reprinted in P. French, T. Uehling, and H. Wettstein (eds), Contemporary Perspectives in Philosophy of Language. Minneapolis, MN: University of Minnesota Press, pp. 383-400. I use the pagination of the latter.

Kaplan, D. (1989). “Afterthoughts". In J. Almog, J. Perry, and H.K. Wettstein (eds), Themes from Kaplan. New York: Oxford University Press, pp. 565-614.

Kennedy, C. (2007). "Vagueness and Grammar: The Semantics of Relative and Absolute Gradable Adjectives". Linguistics and Philosophy 30: 1-45.

King, J.C. (2001). Complex Demonstratives: A Quantificational Account. Cambridge, MA: MIT Press.

King, J.C. (2012). “Speaker Intentions in Context”. Noûs. doi: 10.1111/j.1468-0068.2012.00857.x.

Lewis, D. (1994/1999). “Reduction of Mind”. In S. Guttenplan (ed.), A Companion to Philosophy of Mind. Oxford: Blackwell, pp. 412-30. Reprinted in D. Lewis, Papers in Metaphysics and

27 Thanks to Thony Gillies, Michael Glanzberg, John Hawthorne, Chris Kennedy, Annie Papreck King, and Jason Stanley for helpful discussion. Thanks also to Alexi Burgess and Brett Sherman for helpful comments. A version of this chapter was given at the Rutgers Semantics Workshop in September 2012. Thanks to the audience and my commentator Michael Glanzberg for very useful comments and discussion. 
118 JEFFREY C. KING

Epistemology. Cambridge: Cambridge University Press, 1999, pp. 291-324. I use the pagination of the latter.

Neale, S. (2004). “This, That's and the Other". In A. Bezuidenhout and M. Reimer (eds), Descriptions and Beyond. Oxford: Oxford University Press, pp. 68-182.

Reimer, M. (1991). "Demonstratives, Demonstrations and Demonstrata”. Philosophical Studies 63: 187-202.

Richard, M. (2004). “Contextualism and Relativism”. Philosophical Studies 119: 215-42.

Stanley, J. and Szabo, Z.G. (2000). "On Quantifier Domain Restriction”. Mind and Language 15: 219-61. 